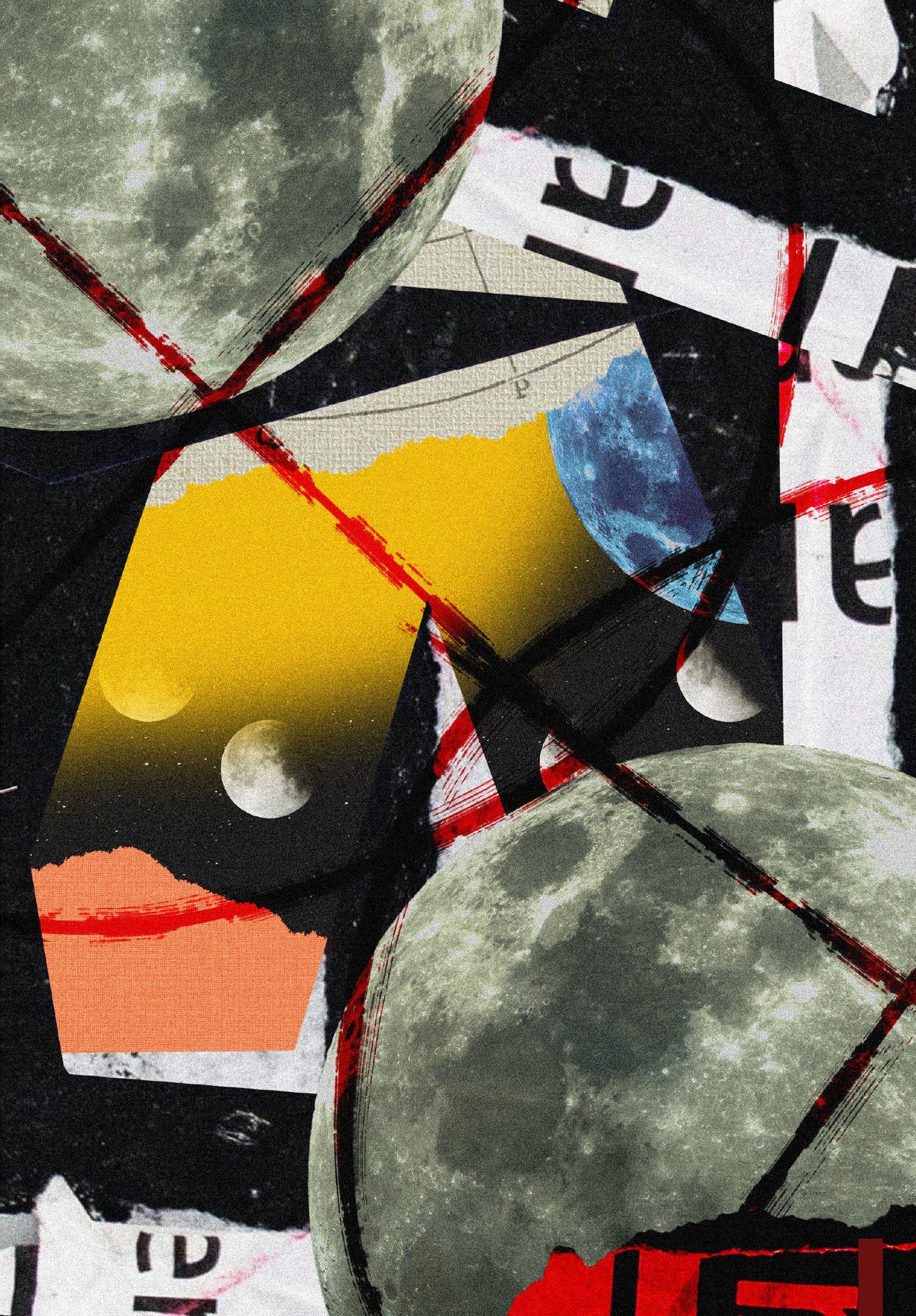




\title{
Elaborando discursos interdisciplinares pelo uso de instrumentos astronômicos históricos
}

\author{
Making interdisciplinary discourses at the use of historical astronomical instruments \\ Ricardo Gutièrrez Garcés \\ Professor substituto da Universidad Nacional de Colombia. Professor de cátedra da Institución Universitaria Digital de \\ Antioquia (Colômbia). Doutorando em Educação pela Universidad Benito Juárez (México). \\ E-mail: rigugar@gmail.com. \\ Roberth De-Carvalho \\ Professor formador e orientador, e assistente em administração, do Instituto Federal de Santa Catarina (IFSC). \\ Doutorando em Educação Cientifica e Tecnológica pela Universidade Federal de Santa Catarina (UFSC). \\ E-mail: orientador.roberth@gmail.com.
}

\section{RESUMO}

Este relato de experiência tem o objetivo de compreender as interlocuções de professores em formação continuada na Educação Básica, no Brasil e na Colômbia, pelo uso de instrumentos astronômicos históricos (IAH), em ações desenvolvidas através do projeto A Astronomia e a Fisica vão à Escola e à Comunidade-AFEC. Tais ações se efetivaram em escolas públicas de Florianópolis, capital de Santa Catarina, Brasil, entre os anos de 2014 e 2015, bem como em uma escola particular no municipio de La Estrella, sul de Medellin, Colômbia, no ano de 2015. Com uma pesquisa exploratória de abordagem qualitativa, apreendemos discursos de professores/as em formação, considerando as seguintes categorias de análise: o estimulo a conteúdos interdisciplinares; o acionamento da pesquisa-ação e o trânsito de variáveis histórico-culturais e tecnocientificas, em nivel microcurricular, na escola básica. Os resultados foram notórios e consistentes no alcance de uma formação discursiva interdisciplinar a partir do uso de IAH.

Palavras-chave: Astronomia, Instrumentos Astronômicos Históricos, Discurso Interdisciplinar, Formação de Professores.

\section{ABSTRACT}

This experience report aims to understand the interlocutions of teachers in continuing education in Basic Education, in Brazil and Colombia, through the use of historical astronomical instruments (HAI) in actions of the A Astronomia e a Física vão à Escola e à Comunidade (AFEC) project. Such actions took place in public schools in Florianópolis, district of Santa Catarina, Brazil, from 2014 to 2015, as well as in a private school in the municipality of La Estrella, south of Medellin, Colombia, in 2015. With an exploratory research with a qualitative approach, we had apprehend discourses of teachers in education considering the categories of analysis: a stimulus to interdisciplinary contents; triggering for research-action; and the transit of historical-cultural and technoscientific variables at the microcurricular level in the basic school. The results had been notorious and consistent in achieving an interdisciplinary discursive formation based on the use of $\mathrm{HAl}$.

Keywords: Astronomy, Historical Astronomical Instruments, Interdisciplinary Discourse, Teacher Education. 


\section{INTRODUÇÃO}

O presente relato apresenta resultados de uma apreensão discursiva pelo uso didático de instrumentos astronômicos históricos (IAH), em diferentes áreas do conhecimento na escola básica. Foi implementado em dois grupos docentes, em Florianópolis, Santa Catarina, Brasil, por um processo de formação continuada, no período de 2014-2015, e em La Estrella, Antioquia, Colômbia, no ano 2015, aliado ao planejamento didático-metodológico de uma escola primária naquele país. Ambas as ações se deram a partir do projeto $A$ Astronomia e a Física vão à Escola e à Comunidade ${ }^{1}$ (AFEC), coordenado pela Universidade Federal de Santa Catarina (UFSC). O projeto objetivou

fomentar o interesse da comunidade escolar e local pela astronomia e ciências afins, aumentar a abrangência de atendimento do Planetário e do Observatório da UFSC junto às escolas da Grande Florianópolis, contribuir para a melhoria na formação de professores de Geografia e Ciências nos niveis médio e fundamental, além de promover a articulação de instituições de ensino, pesquisa, extensão e grupos amadores de Astronomia no processo de popularização do ensino. (UFSC, 2014, s/p.)

Foi executado por um grupo multidisciplinar composto por geólogos/ as, psicólogos/as, engenheiros/as e professores/as de Física, gestionado pelo Departamento de Geociências, do Centro de Filosofia e Ciências Humanas (CFH), da UFSC, bem como por técnicos/as do "Planetário e Observatório Astronômico" dessa universidade; e, também, em parceria com o "Núcleo de Estudos e Observação Astronômica José Brazilício de Souza" (NEOAJBS), do Instituto Federal de Santa Catarina (IFSC), e com o Departamento de Geografia da Universidade do Estado de Santa Catarina (UDESC), para a divisão do trabatho extensionista.

Entre oficinas no Brasil e projetos (ressignificados como circulos de investigación, na Colômbia), como atividades extensionistas previstas na Res. n. 7, de 18 de dezembro de 2018, que normatiza as "Diretrizes para a Extensão na Educação Superior Brasileira" (entre outras providências), as referidas instituições de ensino superior (IES) ampliaram suas propostas de Projetos Pedagógicos relativas aos cursos que ofertam, como: Geografia, Física, Geologia, Engenharias, Ensino de Ciências, mobilizando profissionais, professores/as e estudantes para a comunidade da Escola Básica, com o objetivo de popularizar conhecimentos de Física e de Astronomia.

Nesse sentido, registramos algumas importantes possibilidades didáticas apreendidas nos discursos elaborados entre esses grupos multidisciplinares e a comunidade escolar, característicos de espaços extensionistas e instigadores de curiosidade epistemológica (Freire, 1996), dada a construção coletiva de ambientes metodológicos e democraticamente participativos. Ou seja, "o es- 
tabelecimento de diálogo construtivo e transformador com os demais setores da sociedade brasileira e internacional, respeitando e promovendo a interculturalidade." (Resolução n. 7, 2018, s/p.) Constatamos, também, em ambos os espaços, uma potente variável reclamada em pesquisas e trabalhos acadêmicos nos currículos da escola básica: o ensino-aprendizagem em Astronomia (Langhi, 2004, 2009; Leite, 2002; Bretones, 2006; Langhi \& Nardi, 2009).

Por conteúdos tecnocientíficos da área de Física, em interdisciplinaridade com conhecimentos de outras Ciências da Natureza, da Matemática, das Humanas e das Sociais, segundo orientam Pimenta (2005), Azevedo (2008) e Oliveira (2015), foram elaborados ambientes de pesquisa-ação (as oficinas no Brasil e os círculos na Colômbia), em perspectiva de formação continuada de professores, ou seja, investigar para sua próxima ação pedagógica, tendo como ponto de interlocução a Educação em Astronomia, pelo uso de instrumentos astronômicos históricos (IAH).

Os IAH podem ser classificados conforme o nivel de funcionalidade que alcançam, como: (a) recurso didático ou meio de ensino, em sua função primária como elemento didático mediador, propriamente dito; (b) aparato ou artefato tecnológico, constituido como uma evolução científica em torno de técnicas e práticas sociais de observação do meio; (c) mediador científico, pelo caráter psicopedagógico na compreensão de conceitos, definições e fenômenos físicos em eventos astronômicos; ou (d) objeto de estudo e pesquisa, para compreender contextos histórico-culturais e políticos em sua concepção epistemológica.

\section{SOBRE OS INSTRUMENTOS ASTRONÔMICOS HISTÓRICOS}

Os IAH são artefatos sem lentes (pré-telescópicos), que foram identificados na literatura como instrumentos astronômicos antigos, uma vez que alguns são provenientes do período histórico denominado Idade Antiga. Como aparatos/ferramentas da Astronomia, os IAH foram destinados à observação do Sol e à realização de rituais em comunidades ancestrais, bem como em eventos que marcam a relação entre o céu (cosmo) e o planeta Terra, a exemplo das mudanças de estação para a produção agrícola. Assim, foram construidos os observatórios antigos, com gnômons (varas verticais), para marcar a trajetória do Sol no horizonte, conforme a projeção de suas sombras no chão (Azevedo et al., 2013). O gnômon se converteu no primeiro instrumento de observação astronômica, dada a necessidade de aprimoramento de observações celestes.

Para medir tempos curtos do dia, desde a Antiguidade, utiliza-se o relógio do Sol; e para a noite, na Idade Média, criou-se o nocturlábio, podendo ser utilizado tanto no hemisfério Sul quanto no Norte. Os nocturlábios usam o movimento das estrelas e, no caso do hemisfério Norte, procura-se a Estrela Polar que, se observada (lida) juntamente com a Ursa Menor, pela data do dia, 
possibilita definir a hora aproximada. No hemisfério Sul, o procedimento é similar, utilizando-se o Cruzeiro do Sul.

Destacamos, entre os IAH, a esfera armilar, construida no séc. III, antes da era comum (a.e.c.). A esfera armilar foi utilizada em medições astronômicas e predições de fenômenos da natureza durante muito tempo. Esse instrumento, atualmente, nos possibilita compreender o movimento do Sol e de algumas estrelas. Manipulando sua esfera, com a colocação da latitude do local, é possível encontrar os pontos onde nasce e onde se põe o Sol, assim como a hora. Simula, então, os dias entre 24 e o horas nos círculos polares Antártico e Ártico, os 6 meses de Sol e os 6 meses de escuridão, nos polos Sul e Norte.

Figura 1: Alguns instrumentos astronômicos históricos: astrolábios, esfera armilar e nocturlábio

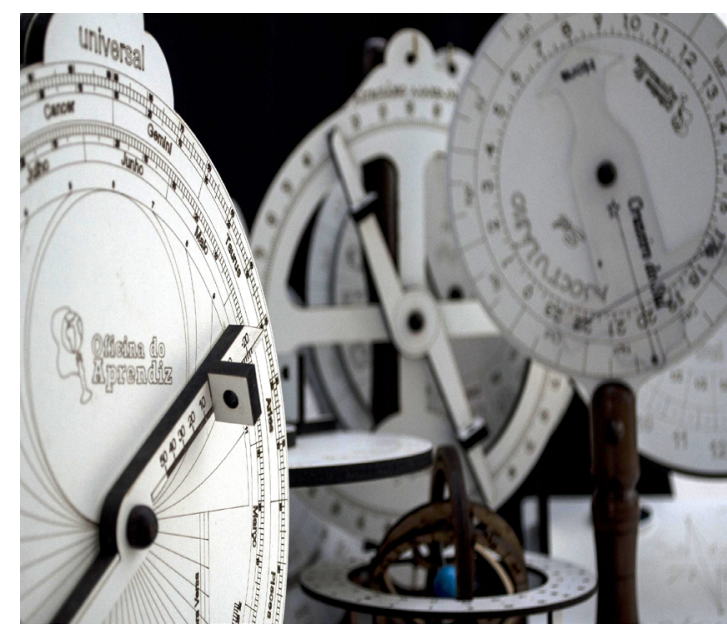

Fonte: Acervo dos autores.

Dentre esses instrumentos, estão o astrolábio e o astrolábio marinho. De invenção árabe, os astrolábios foram de importantíssima utilidade em expedições no mar-oceano, como também no deserto. Utilizados para medição de ângulos e cálculos da posição do Sol e das estrelas, medem latitudes fixas. 0 chamado astrolábio universal, ou católico, mede qualquer latitude.

Frisamos, com isso, o caráter de evolução no uso desses IAH, no âmbito das formações continuadas de professores/as, no Brasil e na Colômbia, responsáveis por uma compreensão histórica, geográfica e tecnológica, em termos de aplicações socioculturais no campo das Ciências da Natureza e da Matemática, bem como em outras áreas do conhecimento. Dessa forma, compreendemos suas potencialidades de formação discursiva no trabalho docente que passamos a relatar. 


\section{METODOLOGIA DE FORMAÇÃO DOS DISCURSOS}

De caráter exploratório, e por uma abordagem qualitativa, conduzimos os procedimentos de registro e apreensão do que chamamos de discursos interdisciplinares, a partir de respostas dadas a questionários e de relatos livres e esclarecidos, respectivamente, por professores/as em Florianópolis, no Brasil, e em Antioquia, na Colômbia.

Assim, tomamos como registros: (1) as respostas argumentativas pelo grupo de professores/as brasileiros/as (referidos/as como P.b.), resguardando seu anonimato, seguidas do número de ordem em que se apresentam no texto; (2) os relatos livres e esclarecidos que transcrevemos dos/as professores/as colombianos/as (referidos/as como P.c.), resguardando seu anonimato, seguidos do número de ordem em que se apresentam no texto. Nesse caso, cada trecho selecionado pontua uma breve discussão da área de conhecimento e das propostas sobre os IAH, selecionados no planejamento do/a professor/a; e. (3) um relato gravado em mídia eletrônica, que transcrevemos ipsis litteris, com teor livre e esclarecido, sobre a experiência apreendida na formação, mantendo a língua oficial do pais. Pontuações e pausas na escrita, nesse registro de gravação, foram feitas a partir dos tempos na fala do/a interlocutor/a.

Asseguramos que toda a coleta de dados para este relato foi realizada em conformidade com as resoluções de ética sob tutela e controle da Comissão Nacional de Ética em Pesquisa (CONEP), junto ao Conselho Nacional de Saúde (CNS), órgão do Ministério da Saúde brasileiro. Destacando-se a Resolução n. 466/2012/CNS, relativa à pesquisa envolvendo seres humanos, para o caso do trabalho no Brasil, em que se pleiteou autorização junto à Gerência de Formação Permanente (GEPE), órgão da Secretaria Municipal de Educação, do município de Florianópolis. Assim como - embora com edição de 2016 cumprimos a Resolução n. 510/2016/CNS, uma vez que procedemos com o pleno esclarecimento e comunicação aos/às participantes da publicação posterior de declarações, questionários, relatos escritos, ou gravados, e registros fotográficos feitos in loco. Quanto ao espaço colombiano, realizamos o livre esclarecimento dos propósitos elaborados, dentro da etapa preliminar de abordagem da escola, junto à direção e à coordenadoria pedagógica, incluindo os/as participantes nas tratativas, dos/das quais obtivemos unanimidade no deferimento.

\section{Em Florianópolis, Santa Catarina, Brasil}

Entre os meses de abril de 2014 e abril de 2015, pelo Projeto AFEC, realizaram-se formações tanto de professores/as em Ciências, da Educação Básica, quanto de professores/as que trabalham no nivel de Educação de Jovens e 
Adultos (EJA), ambas pela rede pública de Florianópolis, Santa Catarina. Por essas formações, eram inseridos os IAH (sendo que, ao final de cada etapa, esses recursos thes eram doados). Com o nome de Oficinas Pedagógicas, como metodologia de formação docente, abordavam-se temas e tarefas de ensino-aprendizagem dentro de variadas áreas do conhecimento, em caráter multidisciplinar (Fazenda, 2011), tanto para docentes experientes quanto para docentes em formação.

Essas oficinas seguiam a metodologia de trabalho em equipe, com um grupo total de 20 (vinte) a 22 (vinte e dois) professores/as por encontro, promovendo discussões abertas, aplicação prática e experimental, trocas de experiências e observações em campo, com a utilização dos IAH, ao fim de cada semestre letivo. Os/As professores/as respondiam a um questionário, tanto na $1^{a}$ quanto na $2^{a}$ fase, com perguntas abertas, para registro de impressões. As perguntas tratavam de aspectos de cunho mais geral, como momento de avaliação pelas/os participantes, sem conduzir ou enfatizar sobre o uso didático específico dos IAH nas disciplinas que ministravam. Para tanto, as perguntas elaboradas nessa fase do projeto foram: a) De que maneira tem utilidade o curso para sua atuação profissional na escola? b) Defina com suas palavras o que pensa sobre o projeto. c) Gostaria de participar no projeto explorando as possibilidades didáticas dos instrumentos e fazendo um observatório solar na escola durante o ano de 2014? Por quê?

Em posterior análise, as respostas revelaram potentes discursos interdisciplinares por seus respondentes, com sugestão de possiveis utilizações dos $\mathrm{IAH}$, como recursos didáticos a serem implementados em sua disciplina. Por tais análises, depreendemos (a posteriori) três categorias, definidas a partir das respostas dos/as professores/as brasileiros/as, sendo: a catalisação de movimentos interdisciplinares; o acionamento para pesquisa-ação e o trânsito de variáveis histórico-culturais e tecnocientificas em nivel microcurricular. Essas categorias, entendidas como potencialidades do discurso, sustentaram nossa análise sobre os discursos dos/as professores/as colombianos/as. Assim, confrontamos intenções, experiências, práticas, ideias, que positivaram pedagogicamente o uso dos IAH.

\section{Em La Estrella, Antioquia, Colômbia}

Por livre consentimento, um grupo de 6 (seis) professores/as de uma escola particular colombiana, no nível de Escola Primária e Secundária, na cidade de La Estrella, foram instigados/as ao desafio de conhecerem (com possibilidade de inserção) os IAH, em seus planejamentos didáticos. Participaram professores/as de diversas áreas do conhecimento, sendo: Ciências Sociais, Matemática, Língua Estrangeira (Inglês, Francês) e Teatro.

Importa ressaltarmos que a proposição curricular dessa Escola compreende uma educação de cunho sócio-histórico e cultural, não se atendo somente à cultura tecnocientífica, uma vez que os/as estudantes são estimulados/as 
à pesquisa investigativa, associada à possibilidade de articular experiências, vivências, histórias, memórias, através de distintos métodos, ferramentas, instrumentos e técnicas. Portanto, reuniões de planejamento, avaliação e discussão são chamadas de círculos pedagógicos, subdivididos em: circulo de exploración ( $3^{\circ}$ ao $5^{\circ}$ anos); circulo de experimentación ( $6^{\circ}$ ao $8^{\circ}$ anos); circulo de proyección ( $9^{\circ}$ ao $11^{\circ}$ anos) e os intercírculos. Ou seja, somando-se 9 anos de estudos, entre os niveis de Escola Primária ( 7 anos: $3^{\circ}$ ao $\left.9^{\circ}\right)$ e Escola Secundária ( 2 anos: $10^{\circ}$ e $11^{\circ}$ ), fases obrigatórias por lei. Os referidos círculos podem culminar em resultados, avaliações e implementações pedagógicas dentro dos circulos de investigación, nos quais nos foi permitido trabalhar com o grupo de 6 professores/as.

Ressaltamos que esses circulos de investigación foram ressignificados nacionalmente, neste relato, como atividade extensionista na modalidade de projetos, seguindo a Resolução n. 7 (2018), conforme interpretamos a proposta curricular daquela escola, em consonância com os Projetos Pedagógicos de Cursos das IFES parceiras.

Assim, o circulo de investigación foi realizado em 28 de agosto de 2015, em que registramos os seguintes momentos relevantes:

a) Sobre uma mesa, à qual se assentavam 5 professores/as, foram dispostos os seguintes IAH: o calendário Maia, a esfera armilar, o relógio do Sol, o calendário gregoriano, o nocturlábio e o astrolábio universal;

b) Após uma breve apresentação sobre o histórico e a funcionalidade dos $\mathrm{IAH}, 3$ dos/as professores/as se motivaram a levá-los para suas aulas, solicitando ao mediador que fizesse um roteiro experimental para aplicá-los;

c) A professora de Ciências Sociais pediu para estudar com mais profundidade a história do astrolábio marinho, no intuito de compreender essa tecnologia utilizada na viagem de Colombo às Américas:

d) O professor de Tecnologia solicitou o relógio do Sol, para reproduzi-lo em papelão com os/as estudantes;

e) Outro professor afirmou o fato de o globo terrestre ser, também, um $\mathrm{IAH}$

f) A professora de Língua Estrangeira (Inglês) auxiliou o grupo com a pronúncia de algumas traduções, e, nesse momento, todos/as concluiram que estava ocorrendo um exemplo de interdisciplinaridade;

g) Por fim, analisou-se o movimento do Sol, levantando-se as seguintes questões: As árvores na Colômbia têm estações? Ficam sem folhas sempre na mesma época do ano?

Com os efeitos produzidos nesses discursos, passamos à discussão de resultados apreendidos nesses espaços de formação. 


\section{DISCURSOS RESULTANTES}

\section{Discurso 1: Estímulo a conteúdos interdisciplinares}

Entre os/as professores/as colombianos/as, a formação de discursos se centrou na orientação e no tempo atmosférico, em que avaliamos um elevado nível de interdisciplinaridade e contextualização científica e investigativa (Delizoicov, Angotti \& Pernambuco, 2002). Implementaram o planejamento com a proposição do globo terrestre, perguntando como incluí-lo em suas aulas.

Uma professora de Ciências Sociais sentiu-se instigada quanto ao uso do astrolábio marinho (Figura 2), buscando compreender como se deu, geograficamente, a viagem de Cristóvão Colombo às Américas. Nesse caso, entendemos o processo de transposição didática de conteúdos via pesquisa-ação (Oliveira, 2015), pelo recorte investigativo em sua curiosidade epistemológica (Freire, 1996).

Figura 2: Professores/as do colégio colombiano usando o Astrolábio Marinho.

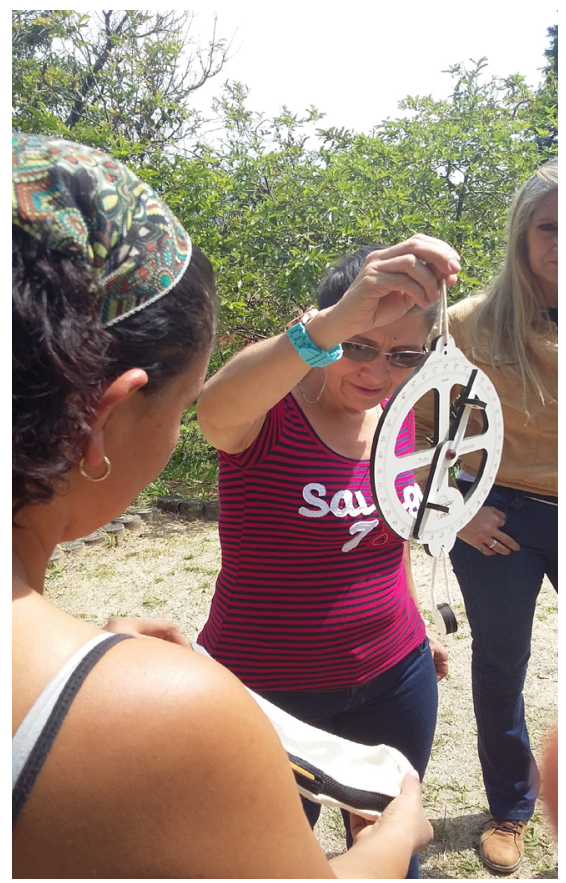

Fonte: Acervo dos autores. 
A partir do relógio do Sol, um professor colombiano fez uma analogia entre conhecimentos de Ciências da Natureza e de História (Oliveira, 2012), conforme descreveu:

P.c.1: En la clase de ciencias hicimos un seguimiento toda una mañana observando los cambios en el reloj de sol, como se "mueve" su sombra, (La sombra del gnomon), como se hace más pequeña a medida que se acerca el medio día y cómo coincide la hora que marca su sombra con la hora real en un reloj convencional. (...) El conocimiento de estos instrumentos astronómicos nos abre la mente para darle una mirada no sólo histórica sino general y desde diversas disciplinas a estas herramientas tan maravillosas que nos han acompañado desde tiempo atrás.

No contexto dos professores brasileiros, destacamos as respostas à pergunta: De que maneira tem utilidade o curso para sua atuação profissional na escola?, dentre as quais selecionamos:

P.b.1: No sentido de entender a parte de Astronomia e divulgar para os outros professores, inclusive os de Geografia.

P.b.2: Vem ao encontro das necessidades na minha função na escola, onde posso trabalhar integrando conteúdos de Ciências, M.A. ${ }^{1} \mathrm{com}$ Geografia, com as pedagogas do $5^{\circ}$ ano.(Professor auxiliar de Ciências)

P.b.3: À disciplina de Ciências, nos $6^{\circ}$ e $7^{\circ}$ anos, quando tratamos de temas e conceitos relacionados ao ambiente e aos seres vivos, e no $9^{\circ}$ ano, relacionando-a a conceitos da Física.

P.b.4: Para poder interagir com outros professores, fazendo o conteúdo ser interdisciplinar.

P.b.5: Em desenvolver novas atitudes, abordando assuntos de Física e Astronomia.

P.b.6: Auxiliou em diferentes formas de abordar os temas, fazendo interlocuções com diferentes disciplinas. Além de possibilitar várias práticas acessiveis.

Vemos a construção de novos sentidos epistemológicos na açãoreflexão, conferindo objetividade e sistematicidade à tarefa docente, dadas as potencialidades do discurso em cada área de conhecimento.

${ }^{2}$ M.A. - meio ambiente. 


\section{Discurso 2: Acionamento da pesquisa-ação}

Na escola colombiana, foram utilizados o gnômon e o globo terrestre, para reconstruir as principais linhas do nascer e do pôr do Sol. Os/As professores/as motivaram a realização do ritual de saudação ao Sol, associado àquela cultura. Nessa perspectiva, por essa tradição, procedeu-se à popularização/divulgação de conhecimentos de Astronomia (Langhi \& Nardi, 2009), cientificizando o senso comum, como oportunidade de marcação espacial ou topológica dos/ as sujeitos/as.

P.c.2: En el área, las planeaciones tienen el propósito de reflejar la articulación mediante competencias, logros, niveles de logro y actividades significativas; es en estas instancias donde el uso de los instrumentos astronómicos antiguos debería tenerse en cuenta, sobre todo como nivel de logro y actividad significativa para garantizar el volver permanentemente a los conocimientos que estos aportan, si no hay constancia en su aplicación seria difícil llegar a entenderlos y realmente vivir la experiencia de observar el mundo de otra manera, conscientes del aqui y el ahora; guiados por las preguntas: ¿Quién soy? ¿Dónde estoy? ¿Qué lugar ocupo en el mundo?

A práxis científica sobre a Astronomia mobilizou elementos de interlocução teórica e prática interferindo sobre a pesquisa-ação. Dessa forma, seus objetos de estudo instigaram questionamentos como: "do quê?" e "por quê?", como situa Azevedo (2008), sendo variáveis orientadoras para um trabalho consciente e sistêmico de pesquisa-ação.

\section{Discurso 3: Trânsito de variáveis histórico- culturais e tecnocientíficas no nivel microcurricular}

Nessa categoria de análise, destacamos as leituras de uma professora colombiana da área de Teatro, refletindo sobre algumas obras literárias e didáticas adotadas em seu planejamento, e que situaram, geograficamente, um/a observador/a no contexto de seus temas, seguindo-se de uma análise de fenômenos naturais. Nesse aspecto, vimos o uso de analogias nas ações de ensino-aprendizagem (Oliveira, 2012), coadunadas com uma Educação em Astronomia. Embora, no entanto, não houvesse uma sistematicidade da tarefa pedagógica. Segue seu relato:

P.c.3: (...) los contenidos que presentan las diferentes dramaturgias (sic) teatrales, la experiencia de la representación fortaleceria con mayor intensidad esa consciencia de lo que soy, de lo que es el otro, de mi relación conmigo, con él y con el mundo; entonces podriamos ser norte, sur, oriente y occidente en el lugar en el que estemos, en nuestro cuerpo, en el del otro y en 
el del universo; entonces podriamos sentir más, que es la mayor búsqueda del arte.

Analisamos, por fim, que tanto o grupo docente das Oficinas Pedagógicas, no Brasil, quanto dos Círculos Metodológicos, na Colômbia, estavam em busca de outras abordagens de conhecimentos científicos, em suas práticas pedagógicas. Constatamos, com isso, que houve uma particular elaboração interdisciplinar de discursos, em ambos os processos de formação desses/as docentes, pelo mote da educação em Astronomia.

\section{CONSIDERAÇÕES FINAIS}

É certo que o estudo da Astronomia pré-telescópica permite a construção e a elaboração artesanal de instrumentos simples de observação celeste. No que se refere ao uso e à funcionalidade de instrumentos astronômicos, esses foram/são tomados como recursos fundamentais em empreendimentos econômicos, sociais, histórico-culturais, ambientais, dentre outros, ao relacionarem fenômenos na Terra com eventos do céu. Desse fato, entendemos que os $\mathrm{IAH}$ foram capazes de instigar, problematizar, reorientar objetos de estudo e, principalmente, mobilizar os espaços extensionistas brasileiro e colombiano, voltados ao campo da formação de professores.

Os formatos de Oficinas Pedagógicas (no Brasil), ou de Círculos Metodológicos (na Colômbia), cumpriram o caráter de integração extensionista pela via da democracia participativa, corroborando com o objetivo principal deste relato de extensão universitária, para compreendermos ambos os espaços de interlocução, em seu caráter interdisciplinar. Vez em que diversas áreas do conhecimento serviram ao trânsito interdisciplinar, intercultural, tecnológico, na Educação Básica tanto do Brasil quanto da Colômbia, relativamente a conhecimentos relacionados à Astronomia e, particularmente, aos IAH. Por analogias, metáforas, questionamentos, avaliamos importantes potencialidades para quaisquer Ciências da Natureza e da Matemática, bem como para outras Ciências: Humanas e Sociais; Linguagens e Códigos; e das Tecnologias de Informação e Comunicação.

As categorias marcadas nesses discursos, quanto à catalisação de movimentos interdisciplinares, ao acionamento da pesquisa-ação e ao trânsito de variáveis histórico-culturais e tecnocientíficas em nível microcurricular, demonstraram que os IAH se convertem em mediadores pedagógicos para a discussão de conceitos que emergem. Desde sua historicidade, passando pelo contexto cultural da época na qual foram desenvolvidos, aliam-se às demandas de seus variados usos, para a observação dos céus com diferenças muito marcadas em cosmovisões e em cosmogonias de diversos povos, possibilitando interessantes abordagens em currículos de Ciências da Natureza. 


\section{Agradecimentos}

Primeiramente, ao Ministério da Ciência, Tecnologia e Inovações (MCTI), através do Conselho Nacional de Pesquisa (CNPq) e da Secretaria de Ciência e Tecnologia para Inclusão Social (SECIS). Em igual medida, aos/às gestores/ as dos espaços formadores: Planetário (disponível em: https://planetario.ufsc. br/) e Observatório Astronômico (disponivel em: https://observatorio.ufsc.br/), ambos vinculados ao Grupo de Estudos de Astronomia (GEA), da UFSC. Como também ao Núcleo de Estudos e Observação Astronômica "José Brazilício de Souza" (NEOAJBS), vinculado ao IFSC; e, ao Departamento de Geografia, da UDESC. 


\section{REFERÊNCIAS}

Azevedo M. N. (2008) Pesquisa-ação e atividades investigativas na aprendizagem da docência em ciências. Dissertação de mestrado, Universidade de São Paulo, São Paulo, SP, Brasil.

Azevedo S. S. M., Pessanha M. C. R., Schramm D. U. S. \& Souza, M. O. S. (2013, abr./jun.) Relógio de sol com interação humana: uma poderosa ferramenta educacional. Rev. Bras. Ensino Fís., São Paulo, 35(2): 1-12. http://dx.doi.org/10.1590/ S1806-11172013000200018

Bretones P. S. (2006) A Astronomia na formação continuada de professores e o papel da racionalidade prática para o tema da observação do céu. Tese de doutorado, Universidade Estadual de Campinas, Campinas, SP, Brasil.

Delizoicov D., Angotti J. A. \& Pernambuco M. M. (2002) Ensino de Ciências: fundamentos e métodos. Editora Cortez, Coleção Docência em Formação. São Paulo, Brasil.

Fazenda I. C. A. (2011) Interdisciplinaridade: história, teoria e pesquisa. $18^{a}$ edição. Editora Papirus. São Paulo, Brasil.

Freire P. (1996) Pedagogia da autonomia: saberes necessários à prática educativa. Editora Paz e Terra. São Paulo, Brasil.

Langhi R. (2004) Um estudo exploratório para a inserção da Astronomia na formação de professores dos anos iniciais do Ensino Fundamental. Dissertação de Mestrado, Universidade Estadual Paulista Júlio de Mesquita Filho, Bauru, SP, Brasil.

Langhi R. (2009) Astronomia nos anos iniciais do ensino fundamental: repensando a formação de professores. Tese de doutorado, Universidade Estadual Paulista Júlio de Mesquita Filho, Bauru, SP, Brasil.

Langhi R. \& Nardi R. (2009) Ensino da astronomia no Brasil: educação formal, informal, não formal e divulgação científica. Rev. Bras. Ensino Fís., São Paulo, 31(4): 4402-4412. https://doi.org/10.1590/S1806-11172009000400014

Leite C. (2002) Os professores de ciências e suas formas de pensar Astronomia. Dissertação de mestrado, Universidade de São Paulo, São Paulo, SP, Brasil.

Oliveira H. R. (2012) Argumentação no ensino de ciências: o uso de analogias como recurso para a construção do conhecimento. Dissertação de mestrado, Universidade Federal de Juiz de Fora, Juiz de Fora, MG, Brasil.

Oliveira K. S. (2015) O ensino por investigação: construindo possibilidades na formação continuada do professor de ciências a partir da ação-reflexão. Disser- 
tação de mestrado, Universidade Federal do Rio Grande do Norte, Natal, RN, Brasil.

Pimenta S. G. (2005, set./dez.) Pesquisa-ação crítico-colaborativa: construindo seu significado a partir de experiências com a formação docente. Educação e Pesquisa, São Paulo, 31(3): 521-539.

Resolução n. 7, de 18 dezembro de 2018. Estabelece as Diretrizes para a Extensão na Educação Superior Brasileira e regimenta o disposto na Meta 12.7 da Lei n. 13.005/2014, que aprova o Plano Nacional de Educação - PNE 2014-2024 e dá outras providências. Diário Oficial da União, n. 243, seção 1, Brasilia, DF, 19 dez. 2018, p. 49.

UFSC. (2014) Planetário da UFSC recebe apoio do CNPq para projeto junto a escolas. Notícias da UFSC, Comunidade. https://noticias.ufsc.br/2014/o1/planetario-da-ufsc-recebe-apoio-do-cnpq-para-projeto-junto-a-escolas/

Data de submissão: 17/08/2020

Data de aceite: 20/10/2020 